\title{
Surface modification of textile electrodes to improve electrocardiography signals in wearable smart garment
}

\author{
Azadeh Soroudi $^{1}$ (D) Niina Hernández ${ }^{1} \cdot$ Jan Wipenmyr ${ }^{2} \cdot$ Vincent Nierstrasz $^{1}$
}

Received: 29 March 2019 / Accepted: 16 August 2019 / Published online: 22 August 2019

(c) The Author(s) 2019

\begin{abstract}
Recording high quality biosignals by dry textile electrodes is a common challenge in medical health monitoring garments. The aim of this study was to improve skin-electrode interface and enhance the quality of recorded electrocardiography (ECG) signals by modification of textile electrodes embedded in WearItMed smart garment. The garment has been developed for long-term health monitoring in patients suffering from epilepsy and Parkinson's disease. A skin-friendly electro-conductive elastic paste was formulated to coat and modify the surface of the knitted textile electrodes. The modifications improved the surface characteristics of the electrodes by promoting a more effective contact area between skin and electrode owing to a more even surface, fewer pores, greater surface stability against touch, and introduction of humidity barrier properties. The modifications decreased the skin-electrode contact impedance, and consequently improved the recorded ECG signals obviously when low pressure was applied to the electrodes, therefore contributed to greater patient comfort. The created contact surface allowed the natural humidity of the skin/sweat to ease the signal transfer between the electrode and the body, while introducing a shorter settling time and retaining moisture over a longer time. Microscopic images, ECG signal measurements, electrode-skin contact impedance at different pressures and times, and water absorbency were measured and reported.
\end{abstract}

\section{Introduction}

Wearable electronics have different applications such as wearable energy-storage devices $[1,2]$ and wearable medical textile [3, 4]. Wearable health monitoring garments can help sustainability by reducing hospital costs and increasing patient 's life quality, however, some technical problems still prevent commercialization and widespread use of medical garments, such as recording low quality body signals when using dry textile electrodes [5-7]. Continuous health monitoring is an extremely important tool for accessing vital physiological functions [8]. For example, ECG (electrocardiogram, which is a skin-surface measurement of the electrical activity of the heart muscle [9]) can be used for physiological monitoring of chronic patients. Electrodes made of electro-conductive material are interfaced between the body and the monitoring system that collects signals from the body.

Azadeh Soroudi

azadeh.soroudi@hb.se

1 Textile Materials Technology, Department of Textile Technology, Faculty of Textiles, Engineering and Business, University of Borås, SE-501 90 Borås, Sweden

2 RISE Acreo, Box 53071, SE-400 14 Gothenburg, Sweden
ECG electrodes sense the ECG biosignals that come from the body as a biological source [10]. In a medical environment, reusable electrodes are usually rigid metal plates of different shapes and sizes [11]. Nowadays, disposable silver/ silver chloride $(\mathrm{Ag} / \mathrm{AgCl})$-gelled electrodes are most commonly used for biosignal measurement; however, these are suitable for short-term monitoring only [12, 13]. For longterm monitoring, the gel used, together with the electrode adhesive, can create rash or skin irritation and even bacterial growth $[13,14]$. Such $\mathrm{Ag} / \mathrm{AgCl}$ electrodes have limited storage time (less than 1 year), and can only be used for a few days because they will undergo drying, which in turn generates noises and errors in the measured signal $[12,15]$. To decrease motion errors at clinics, skin abrasion is carried out to remove the dead skin cells from the surface of the skin and decrease the contact impedance. However, this method is not appropriate for long-term monitoring, since new layers are created on the skin surface after a while, whereas the abrasion process cannot be repeated by the user. Due to the limitations mentioned for $\mathrm{Ag} / \mathrm{AgCl}$ electrodes, researchers have tried to find alternatives for long-term monitoring [16, 17]. In recent years, textile electrodes have been investigated for use in the home and for personal health care systems for continuous health monitoring of cardiac and muscle activity 
$[11,18]$. Textile electrodes can have potential applications from sport to ergonomics, as well as clinical and rehabilitation applications [19]. Dry textile electrodes are expected to overcome the problems of using $(\mathrm{Ag} / \mathrm{AgCl})$-gelled electrodes; however, they show the drawback of a high contact impedance between the electrode and the skin [17, 20-22]. Skin-electrode contact impedance could be representative of valuable information; low skin-electrode impedance shows that skin-electrode interface is good enough to record biosignals well, while high impedance means high signal distortion and noises; even continuous measurement of electrode impedance can be used for estimation of motion artefacts [23-25].

The majority of the textile electrodes reported are based on metal-coated yarns or fine metal wires, woven or stitched into conventional textile fibres [26]. Different materials and fabrication methods have been presented so far and some are commercially available [12, 27, 28]. Apart from skin impedance, textile electrodes have been studied regarding skin-electrode impedance changes over time [16, 29, 30], visual comparison of recorded ECGs using prepared electrodes and reference electrodes [30-33], biocompatibility and skin response [31], power spectral density [32, 33], and evaluation of electrode electrical properties [16].

The reported high skin contact impedance either limits the use of dry textile electrodes when very small signals must be recorded, or leads to doubts about the signal quality [30, 31, 33, 34]. There are different factors affecting the skin contact impedance; for example, contact pressure [35-37] and humidity [38]. Moreover, other than the magnitude of the impedance, its stability is also important; this determines the settling time and signal quality [39]. For ECG measurement, knitting has been the most widely applied technology so far [11, 40, 41]. However, knitted stainless steel electrodes show a poor skin-electrode contact impedance and a high sensitivity to motion artefacts [41].

Intrinsically conductive polymers are another option to transform nonconductive textiles into flexible and reliable conductors [42]. (Poly)-3,4-ethylenedioxythiophene doped with poly (styrene sulfonate) (PEDOT:PSS) is one of the most used, due to its excellent characteristics such as superior electrochemical properties, biocompatibility and thermal stability [8, 20, 43-45]. However it is believed that PEDOTPSS shows hydrogel properties under wet conditions, which reduce its mechanical strength according to its water content [46], and in turn results in exfoliation from the substrates and a loss of electrical conductivity. Recently, a comparative study on silver-plated and PEDOT:PSS coated fabrics for long term monitoring [47] has shown that for both types of textile electrodes, all electrocardiographic signals were identifiable, despite higher contact impedance of PEDOT:PSS textile electrodes. The initial surface conductivity and tolerance against repetitive washing was better in PEDOT:PSS only in the case that higher amounts of PEDOT:PSS were used (pure cotton and $12.8 \mathrm{wt} \%$ PEDOT:PSS).

Silver-coated yarns have been reported to have a low impedance, good biocompatibility and high conductivity $[38,48]$. The most widely used inorganic antimicrobial additives are based on silver and copper [49], which together with biocompatibility makes silver a good candidate for skin contact. There are already commercially available silver-coated fibres and fabrics for electrode fabrication. However, it is reported that silver electrodes need moisture to record signals without artefacts, especially if the body is moving [38]. That is why more research is needed in order to improve the quality of signals recorded by silver electrodes.

This study is done within a multidisciplinary research project, WearITmed [50, 51], that has developed a wearable garment (Fig. 1) with integrated sensors for clinical evaluation of neurological diseases such as epilepsy and Parkinson's disease [52]. The aim of this study is the improvement of silver plated textile electrodes embedded in the shirt for recording ECG signals. The initial prototype electrodes were made using Shieldex, a commercially available conductive knitted fabric (Statex, Germany) [53, 54]. However, for longterm monitoring, adding moisture to such silver-based electrodes is not a good solution, as the electrodes dry out after a few hours, leading to errors or even measurement interruption. A conductive elastic silver/polyurethane paste was prepared, and electrodes were modified with regard to surface characteristics and humidity barrier properties. Modified and unmodified electrodes were analysed concerning skin-electrode impedance, recorded ECG signals, water absorbency and the surface morphology using optical microscopy.

\section{Materials and methods}

\subsection{Materials}

The initial electrodes in the WearITmed smart shirt were made of a ' $4 \mathrm{~cm} \times 6 \mathrm{~cm}$ ' silver-plated knitted fabric (Shieldex ${ }^{\circledR} \mathrm{P} 130$, Statex, Germany). To improve the

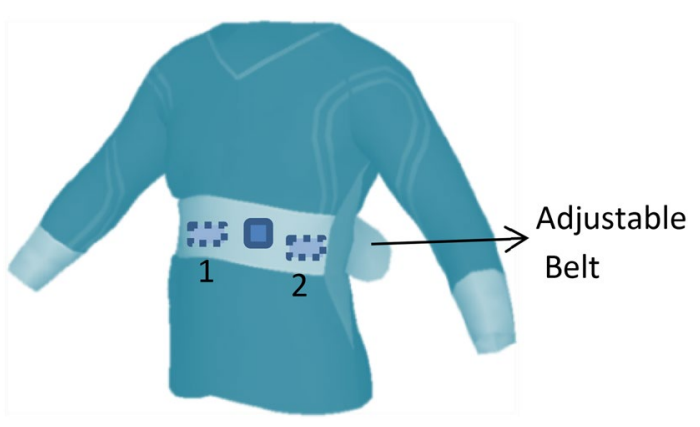

Fig. 1 WearITmed smart shirt with two Shieldex electrodes (1 and 2) 
electrode's surface functionality, an electro-conductive paste was made using hydrophilic polyurethane with high elasticity (Tubicoat, CHT Smart Chemistry) and silverplated copper flake (eConduct Copper 421000, Eckart, Germany). As curing agent, Tubicoat Fix, a polyfunctional crosslinking agent, was used to increase the washing stability of crosslinkable polyurethane. The silver-plated copper flakes had typical particle size (diameter) of 13-71 $\mu \mathrm{m}$. Polypropylene (PP) tape, Trend from Muroll-Austria was used as barrier film for lamination. The PP tape was made of a $28 \mu \mathrm{m}$ thick PP film, and total thickness (PP + adhesive layer) was $48 \mu \mathrm{m}$.

\subsection{Fabrication methods}

\subsubsection{Fabrication of hydrophilic elastic conductive paste}

A mixture of hydrophilic polyurethane and silver-plated copper flakes was stirred magnetically at $700 \mathrm{rpm}$ for $1 \mathrm{~h}$ at room temperature. The final concentration of conductive particles was calculated to be $30 \mathrm{wt} \%$. An amount of $9 \mathrm{~g} / \mathrm{L}$ crosslinking agent was added to the paste and mixed under the same conditions for a further 5 min immediately before coating.

\subsubsection{Electrode fabrication}

Three pairs of electrodes, each of size of ' $4 \mathrm{~cm} \times 6 \mathrm{~cm}$ ' were prepared. Support foam was used in all the electrodes to improve the pressure distribution and contact between electrode and skin. The first pair were unmodified Shieldex. For the second pair, PP/Shieldex, a PP film was laminated to the back of the Shieldex to act as humidity barrier. To improve the electrodes further, a third pair of electrodes, PP/Shieldex/coating, was prepared. First the front side of the Shieldex was blade-coated with the prepared elastic conductive paste and cured for $10 \mathrm{~min}$ at $90{ }^{\circ} \mathrm{C}$. Then, the back side of the electrode was laminated with the same PP film (Fig. 2). PP film was selected since it a

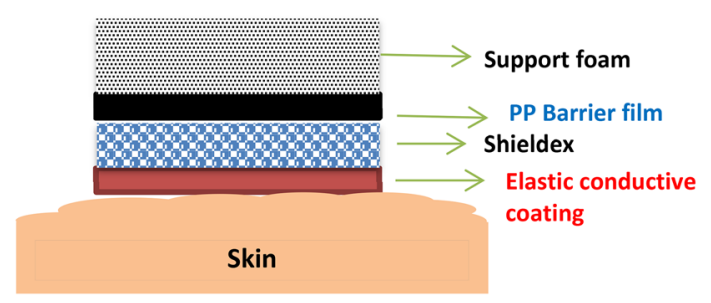

Fig. 2 Modified electrode construction in PP/Shieldex/coating polymer with one of the highest barrier properties against humidity $[55,56]$.

\subsection{Measurement methods}

\subsubsection{Microscopic images}

A Nikon SMZ800 stereomicroscope with magnification range up to $\times 8(1$ to $\times 8)$ was used to study the surface of skin (for tested individual), Shieldex and modified Shieldex. The maximum zoom of the optical microscope $(\times 8)$ was selected to record the surface image in all the samples.

\subsubsection{ECG examination}

For ECG measurements, the prepared electrodes 1 and 2 were installed (in completely dry state) on a WearITmed smart shirt over a pre-located adjustable belt (for tightening) under the breast (Fig. 1) and connected to the electronics, which was embedded in the front side of the shirt between the electrode-1 and 2. The ECG reference electrode was a pure Shieldex which was constantly placed in the left arm's zone [51].

A sampling frequency of $100 \mathrm{~Hz}$ was used for the ECG measurement by each electrode pair and the measurements carried out for a period of 10 min while the shirt was worn by a 39-year-old woman, sitting still and typing with a computer (small movements of the upper body). Two levels of pressure ( 3 and $9 \mathrm{mmHg}$ ) were applied to the electrodes using the shirt's adjustable belt. The raw data collected in the shirt was transferred to a PC via USB connection. The software MATLAB was used for plotting data. The procedures followed were in accordance with the ethical principles of the Declaration of Helsinki and the guidelines for Good Clinical Practice (GCP), 1964, revised 2000.

\subsubsection{Impedance and pressure measurement}

An electrode impedance meter (Grass, Model F-EZM5, W. Warwick, RI, USA) was used to measure the skin-electrode impedance. The F-EZM5 measures impedance at $30 \mathrm{~Hz}$ in $\mathrm{k} \Omega$ for applied electrodes used in various diagnostic procedures such as EKG, EMG (electromyography) and evoked potentials. The digital liquid crystal display (LCD) indicates impedance with an accuracy of $\pm 5 \%$ at $30 \mathrm{~Hz}$. The Grass impedance meter can measure AC impedance (resistance and capacitance) in the range of $0.2-200 \mathrm{k} \Omega$ and can be used in hospitals to check if an electrode is suitable for ECG measurement or not. In this study, three-electrode method was used to measure the impedance: two of electrodes were commercially available $\mathrm{Ag} / \mathrm{AgCl}$ electrodes, one as ground electrode connected to the leg, and the other one as reference electrode 
connected to the left chest. The third electrode was the measured one (either a Shieldex-based textile electrode with size of ' $4 \mathrm{~cm} \times 6 \mathrm{~cm}$ ', or standard $\mathrm{Ag} / \mathrm{AgCl}$ for comparison) and positioned under the breast with $10 \mathrm{~cm}$ distance from the reference electrode; the position was the same for all the measurements. A separate adjustable belt (similar to the shirt"s belt) was used to apply pressure on the measured electrode. Reference and ground electrodes were constantly $\mathrm{Ag} / \mathrm{AgCl}$ and unchanged in all the measurements. The configuration is shown in Fig. 3. The mean values of four measurements were reported for impedance of textile electrodes; it means that the Reference and Ground electrodes were constant, while four samples of each textile electrode were measured, having the same size of (' $4 \mathrm{~cm} \times 6 \mathrm{~cm}$ '). The maximum observed standard deviation was $\pm 5 \%$. The pressure applied on the measured electrode was controlled by the adjustable belt and measured using a Pico Press (Microlab Electronics, Italy). The instrument uses a circular transducer placed between the skin and the test sample [57]. Different pressures were applied on measured electrodes, and data were read at two different times. More details will be explained in electrode characterization section.

\subsubsection{Water absorbency}

To measure the water absorbency, first a piece of each sample with the size of ' $4 \mathrm{~cm} \times 6 \mathrm{~cm}$ ' was dried in a vacuum chamber (Vacuo-Temp, J.P. Selecta) under $70 \mathrm{mmHg}$ vacuum pressure and $40{ }^{\circ} \mathrm{C}$ for $10 \mathrm{~min}$ to remove any humidity. After drying, the sample was weighed and left in distilled water for 2-30 min. The weight of each sample was measured after drying the sample surface with cotton. The weight percentage of absorbed water based on the initial sample weight was calculated.

\section{Results and discussion}

\subsection{Microscopic images and modification of textile electrodes}

Microscopic images in Fig. 4a-c show that the efficient contact area between the surfaces of skin (a) and the knitted Shieldex fabric (b) is actually too low. Furthermore, the Shieldex is quite porous, which may affect the signal recording negatively by passing the humidity through the pores. That is why two levels of modifications were applied to the Shieldex, as explained above (2.2.2 Electrode fabrication).
Fig. 3 Configuration of impedance measurement using three electrodes

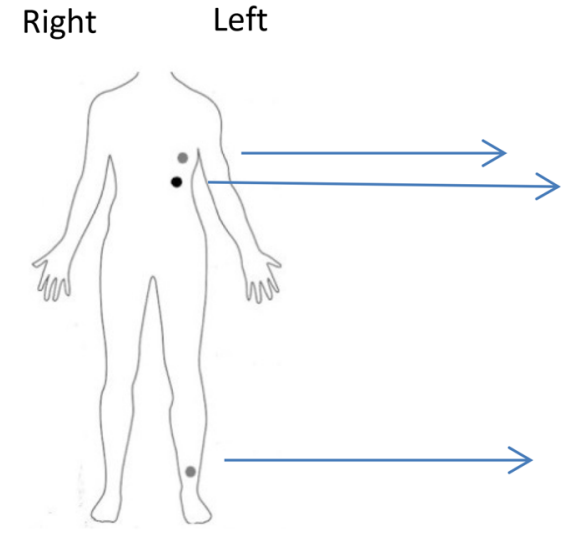

Reference electrode $(\mathrm{Ag} / \mathrm{AgCl})$

Measured electrode under the adjustable belt (Textile electrode, or $\mathrm{Ag} / \mathrm{AgCl}$ for comparison)

Ground electrode $(\mathrm{Ag} / \mathrm{AgCl})$
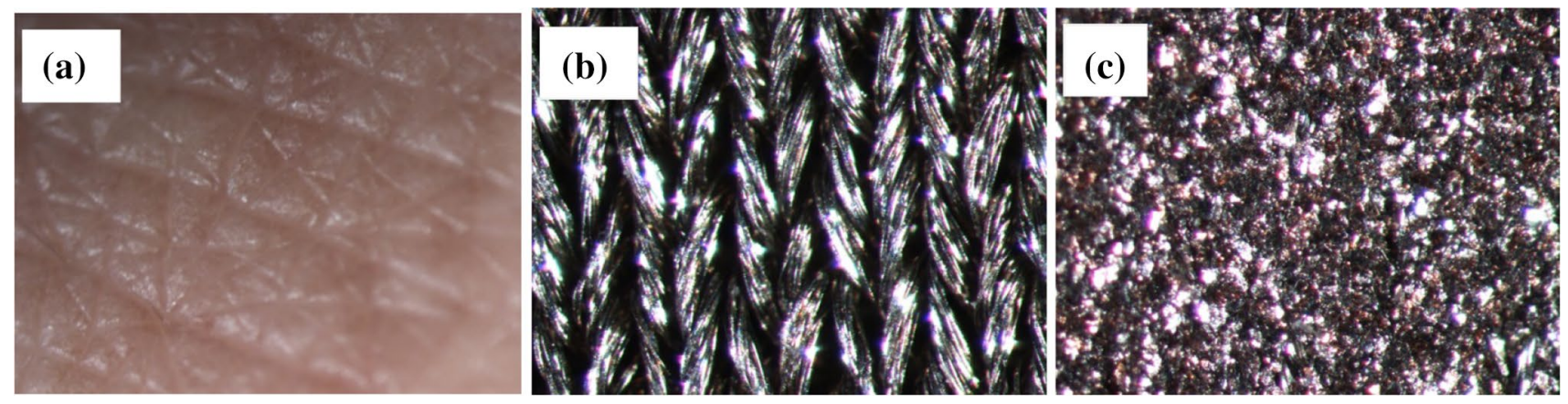

Fig. 4 Optical microscopy $(\times 8$ zoom) of the skin surface for tested individual (a), unmodified Shieldex (b), and modified coated Shieldex (c) 
An elastic conductive coating was prepared and applied to the front side of the Shieldex electrode in order to improve the effective contact area between the skin and the electrode surface; the coated surface is presented in Fig. 4c. Modification by this formulation might help the signal recording in at least three ways because the elastic surface coating is more even (more efficient skin-electrode contact), has far fewer pores than Shieldex (less humidity transfer, bigger contact area), and might sit better on skin surfaces, due to its elastic nature.

A third observation (Fig. 5) was that the surface of the applied coating is firmer than Shieldex, which in turn gives a structure more stable against touch. This could improve the sensitivity of the electrode against patient movements, leading to fewer motion artefacts in the recorded signals. The influence of a firmer surface, as well as that of a fourth parameter, humidity, will be discussed later.

\subsection{Experimental results of ECG measurement}

As explained in the experimental section, two levels of pressure ( 3 and $9 \mathrm{mmHg}$ ) were applied to the electrodes, using the shirt's adjustable belt; we called them low and medium pressure recording. The results of ECG measurement under low and medium pressure conditions are presented in Fig. 6, under left and right column respectively. A clear observation is that the influence of modification is far more visible when low pressure is applied to the textile electrodes. As can be seen from the signals recorded at low pressure (Fig. 6-left column), unmodified Shieldex shows severe levels of visible noise. Lamination of Shieldex with PP film decrease the signal noises to some extent, and further modification of the surface with elastic conductive coating results in even higher quality signals, with far less visible noises compared to the unmodified electrode.

When a higher pressure is applied to the electrodes (Fig. 6-right column), even unmodified Shieldex has recorded a rather good quality signal and the effect of modification is not visible compared to that seen in signals taken at lower pressure. Therefore we conclude that the effect of modification on improving signal quality is significant and consequently visible when low pressure is applied to the electrodes. Since low pressure on the electrode leads to greater comfort according to the test object expression, therefore the modification of Shieldex has contributed both to patient comfort and signal quality. Liu et al. [58] have also reported that pressure plays a key role in garment comfort and should not be too high or too low.

Looking at the plots under a lower zoom (a wider range of data) in Fig. 7, can indicate the stability of the electrodes against patient small movement when the person is sitting still; there are fewer motion artefacts when using PP/Shieldex/coating compared to unmodified Shieldex. One reason may be the firmer structure observed in PP/Shieldex/coating than in unmodified Shieldex, as the latter easily developed wrinkles when touched, which can result in less effective contact with the skin, as shown in Fig. 5. The other possible reasons, such as a higher humidity in the modified Shieldex-skin interface will be discussed later.

\subsection{Electrode characterization}

Impedance was measured for all three textile-based electrodes, as well as an $\mathrm{Ag} / \mathrm{AgCl}$ electrode for comparison, using the method described before. A separate adjustable belt was used to apply different pressures to the measured electrode. The measurements were carried out under four levels of pressure: $\mathrm{P}=3,9,18$ and $28 \mathrm{mmHg}$. For each electrode sample, the impedance was read at two different times: zero-time (as soon as placed on skin) and after $5 \mathrm{~min}$ contact with skin $(t=0$ and $t=5$ min, respectively). All the measured data are presented in Table 1 . The term 'NA' in Table 1 means that the impedance has been higher than $200 \mathrm{k} \Omega$ and therefore not measurable using Grass impedance meter.
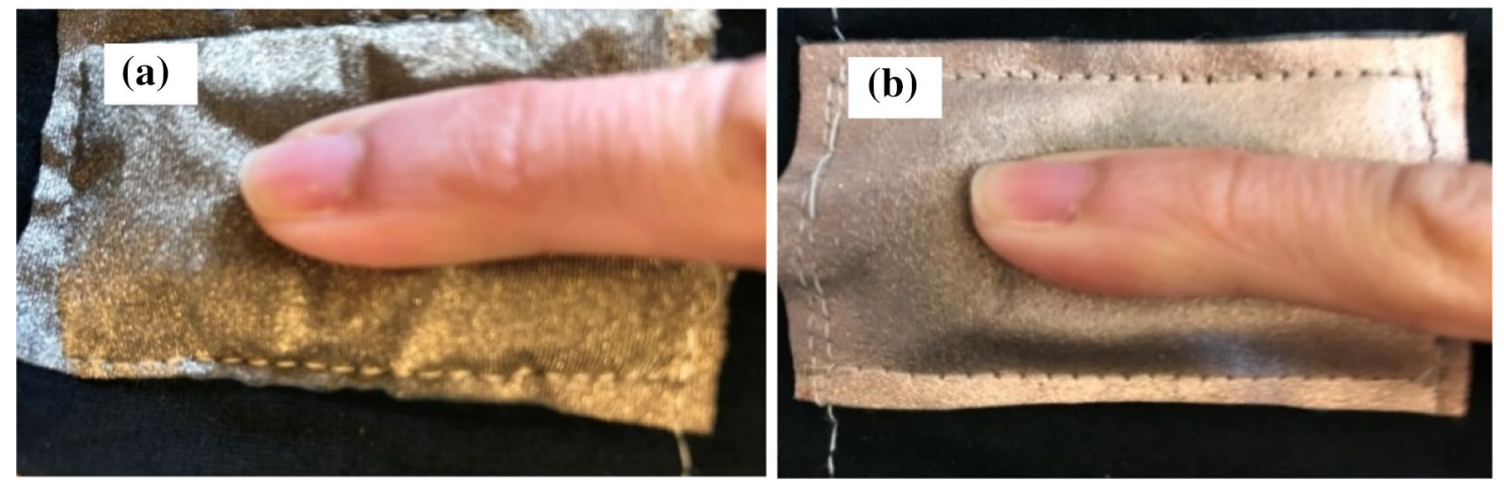

Fig. 5 Stability of unmodified and modified Shieldex against touch: a unmodified Shieldex, b PP/Shieldex/coating 

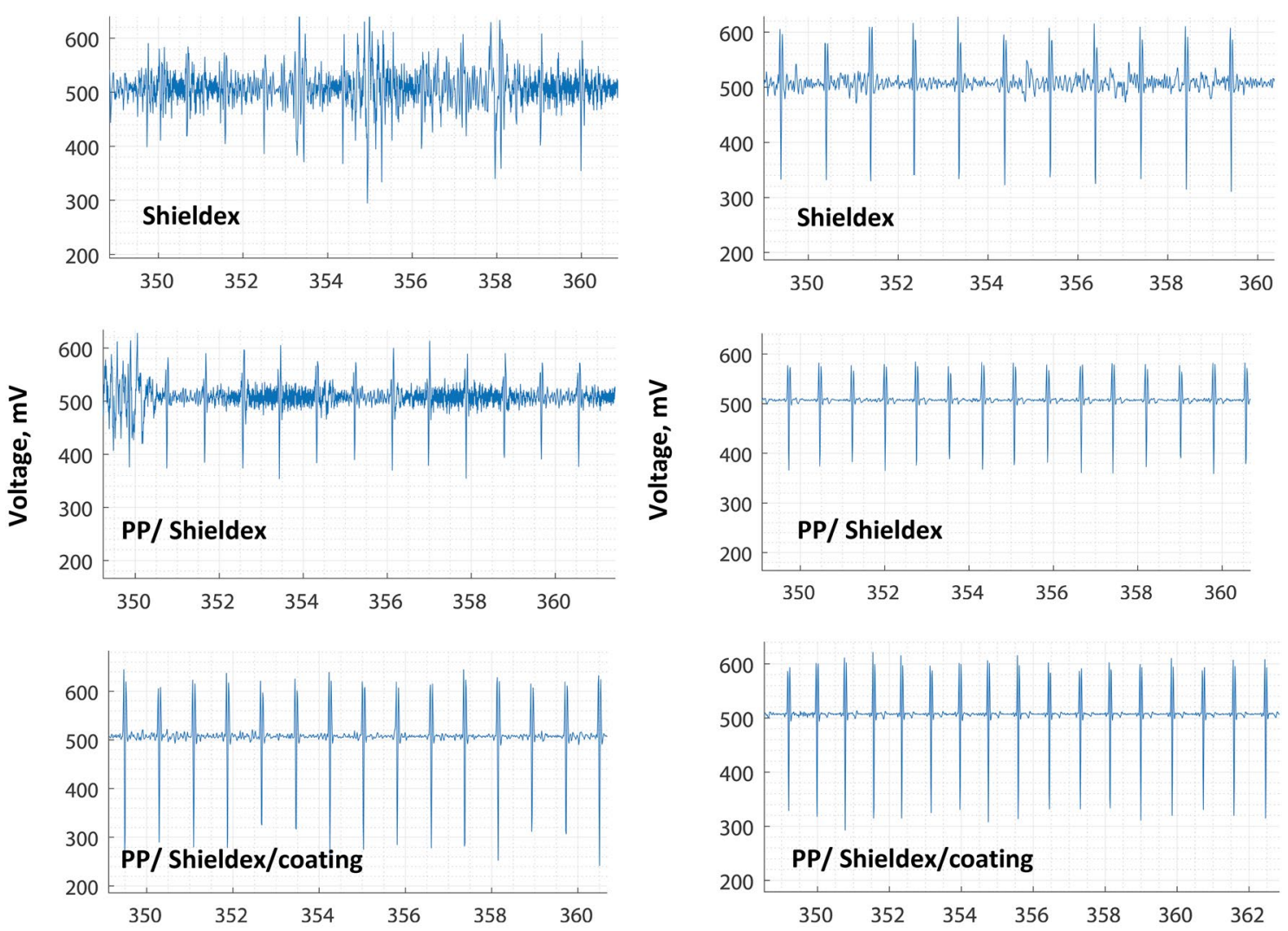

Time, Second

Time, Second

Fig. 6 ECG measurement; left column: low pressure applied to electrodes ( $3 \mathrm{mmHg}$ ), right column: medium pressure applied to electrodes $(9 \mathrm{mmHg})$
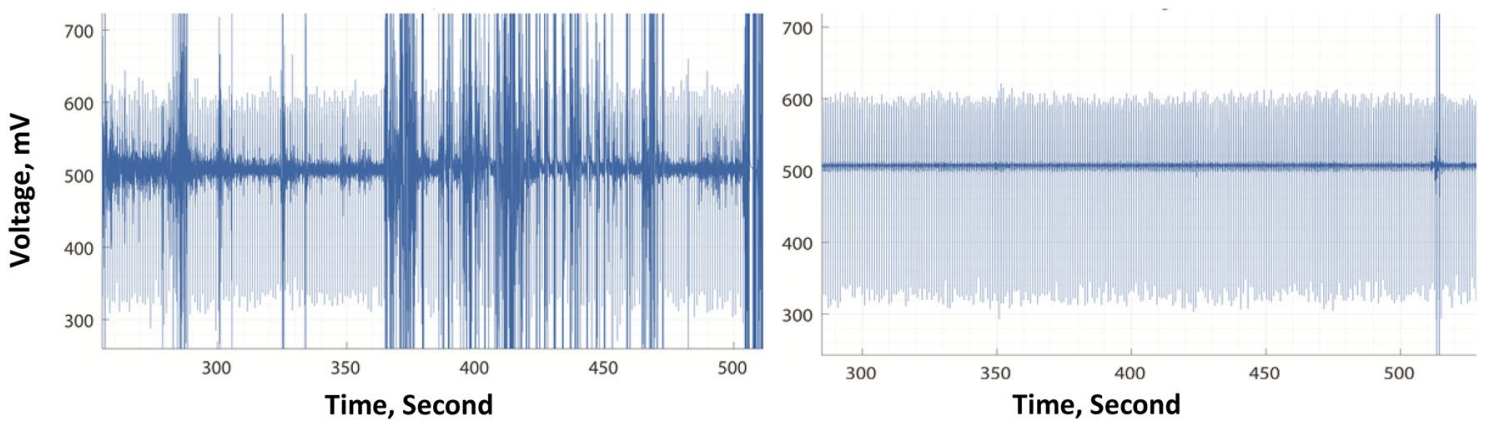

Fig. 7 Motion artefacts observed under a lower zoom (a time period of $200 \mathrm{~s}$ ) when wearer is sitting still and typing by both hands. Left: unmodified Shieldex; Right: modified Shieldex (PP/Shieldex/coating). Applied pressure: $3 \mathrm{mmHg}$ for all electrodes

Table 1 Electrode-skin contact impedance $(\mathrm{k} \Omega)$ for different sample electrodes under different applied pressures ( $\mathrm{P}=3-28 \mathrm{mmHg}$ ); impedance number read at zero-time and after $5 \min (t=0$ and $t=5)$

\begin{tabular}{|c|c|c|c|c|c|c|c|c|c|}
\hline \multirow[t]{2}{*}{ Sample electrode } & \multicolumn{2}{|l|}{$\mathrm{P}=3$} & \multicolumn{2}{|l|}{$\mathrm{P}=9$} & \multicolumn{2}{|c|}{$\mathrm{P}=18$} & \multicolumn{2}{|c|}{$\mathrm{P}=28$} & \multirow{2}{*}{$\begin{array}{l}\mathrm{mmHg} \\
\min \end{array}$} \\
\hline & $\mathrm{t}=0$ & $t=5$ & $\mathrm{t}=0$ & $\mathrm{t}=5$ & $\mathrm{t}=0$ & $t=5$ & $\mathrm{t}=0$ & $\mathrm{t}=5$ & \\
\hline Shieldex & NA & NA & 168 & 152 & 148 & 141 & 142 & 135 & $\mathrm{k} \Omega$ \\
\hline PP/shieldex & NA & NA & 172 & 145 & 155 & 114 & 100 & 80 & $\mathrm{k} \Omega$ \\
\hline $\mathrm{PP} /$ shieldex/coating & NA & 185 & 156 & 100 & 102 & 86 & 71 & 58 & $\mathrm{k} \Omega$ \\
\hline $\mathrm{Ag} / \mathrm{AgCl}$ for comparison & 135 & 119 & 116 & 102 & 102 & 97 & 97 & 94 & $\mathrm{k} \Omega$ \\
\hline
\end{tabular}


Fig. 8 The pressure sensitivity of electrode-skin contact impedance at different reading Times: Left: $\mathrm{t}=0$, Right: $\mathrm{t}=5 \mathrm{~min})$
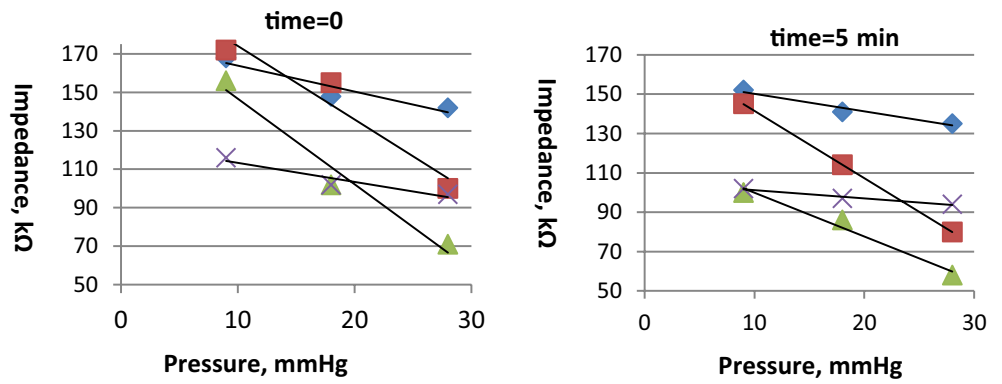

$\checkmark$ Shieldex

PP/Shieldex

$\triangle P P /$ Shieldex/coating

$\times$ Reference-
As data in each column of Table 1 show, PP/Shieldex/ coating shows lower contact impedance than PP/Shieldex and unmodified Shieldex; each column presents different pressure and time conditions. The other observation is that under 'special' conditions, $\mathrm{PP} /$ Shieldex/coating is the only sample that shows lower impedance than the reference $\mathrm{Ag}$ / $\mathrm{AgCl}$ electrode: at $\mathrm{P}=28$, both $\mathrm{t}=0$ and $\mathrm{t}=5 \mathrm{~min}$, and at $\mathrm{P}=9$ and $\mathrm{P}=18$ when $\mathrm{t}=5 \mathrm{~min}$. However as shown in Table 1 , at very low pressure $(\mathrm{P}=3 \mathrm{mmHg})$ and zerotime, the reference $\mathrm{Ag} / \mathrm{AgCl}$ electrode is the only one whose impedance is measurable; whereas at low pressure $(\mathrm{P}=3 \mathrm{mmHg}$ ) and $\mathrm{t}=5 \mathrm{~min}, \mathrm{PP} /$ Shieldex/coating also shows an impedance low enough to be measurable. The observations could be due not only to a better contact with the skin because of the surface properties of the PP/Shieldex/coating as mentioned before, but also to its barrier properties that build up and keep natural body humidity between the skin and coating, especially after 5 min being in contact with the skin.

Figure 8 presents the sensitivity of electrode-skin contact impedance to the applied pressure for different electrodes. As expected, in all the samples and for both measurement times ( 0 and $5 \mathrm{~min}$ ), increasing pressure decreases the contact impedance due to a better contact between electrode and skin. If we consider the slope of each line, data obtained at zero-time (left plot) show that the pressure sensitivity of contact impedance for electrodes follows this order: PP/Shieldex/coating $>$ PP/Shieldex $>$ Shieldex $>$ reference $(\mathrm{Ag} / \mathrm{AgCl})$. Since the polyurethane coating is elastic, it can be expected to show the highest pressure-sensitivity of contact impedance of the coated electrodes. However, the order of pressure sensitivity of contact impedance measured at $\mathrm{t}=5$ min changes to: $\mathrm{PP} /$ Shieldex $>\mathrm{PP} /$ Shieldex/coating $>$ Shieldex $>$ reference $(\mathrm{Ag} / \mathrm{AgCl})$. This may be due the lower humidity absorbency of PP/Shieldex/coating compared to PP/ Shieldex, which in turn leads to lower contact impedance, as humidity accumulates between the skin and the coated surface, and thus lessens the dependency of impedance on pressure. It can be concluded that when leaving the electrode on the skin, the humidity also plays a role, along
Table 2 Water absorption of immersed samples

\begin{tabular}{lll}
\hline Material & \multicolumn{2}{l}{$\begin{array}{l}\text { Water absorption (wt\% of initial } \\
\text { weight) }\end{array}$} \\
\cline { 2 - 3 } & After 2 min & After 30 min \\
\hline Shieldex & 47 & 62 \\
PP/shieldex & 33 & 54 \\
Shieldex/coating & 13.4 & 17.7 \\
PP/Shieldex/coating & 0.9 & 5 \\
\hline
\end{tabular}
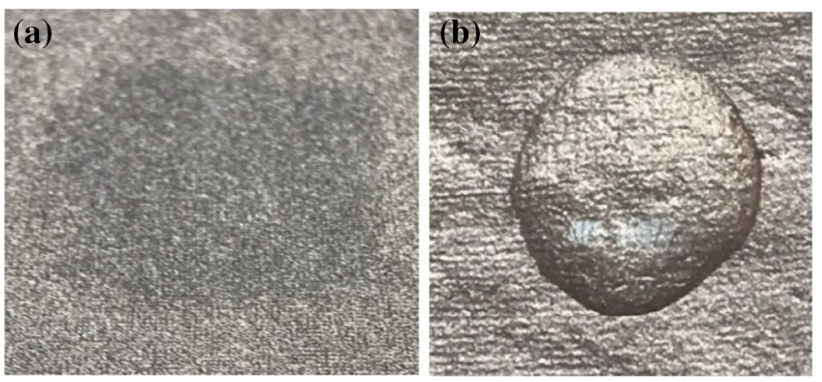

Fig. 9 Water droplet left $\mathbf{a}$ on Shieldex after $1 \mathrm{~s}$ and $\mathbf{b}$ on conductive polyurethane-coated Shieldex after $30 \mathrm{~min}$

with elasticity and applied pressure. The water absorbency of the electrodes will be discussed below.

\subsection{Water absorbency}

As shown in Table 2, the maximum water absorbency is observed in unmodified Shieldex, and the minimum in PP/ Shieldex/coating, because both PP and the prepared polyurethane elastic coating are barriers against humidity.

Figure 9 shows a droplet left on the coated surface for $30 \mathrm{~min}$, as well as a droplet on Shieldex that disappeared as soon as it was put on the surface. As seen in Table 2, Shieldex/coating exhibits lower water absorbency than PP/ Shieldex; mainly because the water can be trapped between the PP layer and Shieldex. Although the water absorbency was tested for samples immersed in water, the results can 
Fig. 10 Influence of adding humidity barrier to electrodes in contact with the skin
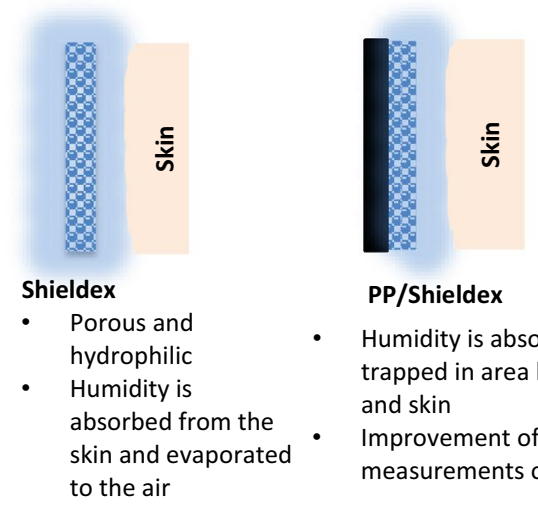

PP/Shieldex

Humidity is absorbed and trapped in area between PP and skin

Improvement of measurements over time

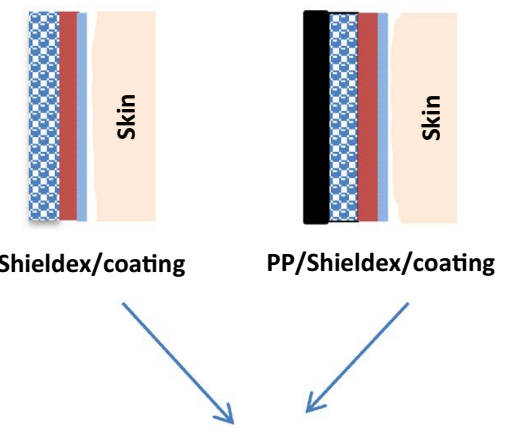

The majority of humidity trapped between skin and
coating:
- Sweat acting as electrolyte and helping signal
transfer
- Shorter settling time to record good signals however be utilized to predict the behaviour of electrodes on skin, where the electrode is in contact with humidity from the skin.

A schematic of the condition is presented in Fig. 10, where adding humidity barrier to the electrode, especially in contact with skin, can improve the quality of signal transfer, because the natural humidity (sweating) can accumulate between skin and electrode surface, and acts as electrolyte.

\section{Conclusions}

The knitted silver-plated textile electrodes were modified in order to make skin-friendly electrodes with moist-active surfaces having the ability to record high quality ECG signals without losing moisture over a longer time while making an efficient contact area with the skin. Laminating the back of Shieldex electrodes with polypropylene as the only modification could improve the electrode's function to some extent by reducing the signal noises slightly under low pressure, and decreasing the skin contact impedance when electrodes left on the skin of tested individual for $5 \mathrm{~min}$. An elastic electro-conductive polyurethane was made to coat the front side of the Shieldex electrodes. The coated layer in contact with the skin could improve the functionality of the electrode due to a combination of several observed factors: (1) a higher contact area between the electrode and skin due to a more uniform and even surface, as well as having fewer pores; (2) a firmer surface that improves the stability of the contact area against touch, leading to fewer movement artefacts; (3) a higher humidity barrier between skin and the electrode surface, letting the natural humidity of the body/sweat to accumulate in the interface and ease the signal transfer and shorten the settling time for recording good signals. These modifications improved the ECG signals visibly when low pressure was applied to the electrodes, therefore leading to a greater garment comfort based on the test object expression, and a previous study showing the relation between pressure and clothing comfort [58]. The stability of the conductive coating against multiple washing should be investigated in the future.

Acknowledgements Open access funding provided by University of Boras. This project is a part of a multidisciplinary project, WearITmed, funded by Stiftelsen för Strategisk Forskning in Sweden, and we would like to thank all of our partners in the consortium and acknowledge the support of our colleagues at Högskolan I Borås. Swedish School of Textiles: Fernando Seoane Martinez, Emanuel Gunnarsson, Veronica Malm, Ellinor Niit, Catrin Tammjärv, Ulrika Noren, Anja Lund, Karin Rundquist. Department of Work Life and Social Welfare: Leif Sandsjö. Sahlgrenska Academy: Margit Alt Murphy, Filip Bergquist, Kristina Malmgren, Dongni Johansson, Katharina Stibrant Sunnerhagen, Bertil Rydenhag, David Krýsl, Anneli Ozanne, Katinka Almrén; RISE Acreo AB: Fredrik Ohlsson, Sara Bogren, Peter Björkholm, Amin Ojani, Borys Stoew, Kaies Daoud, John Rösevall; Swerea: Bengt Hagström, Helen Karlsson, Hans Grönquist, Kristina Hellström, Erik Nilsson, Joraine Rössler, Åsa Lundevall.

Open Access This article is distributed under the terms of the Creative Commons Attribution 4.0 International License (http://creativeco mmons.org/licenses/by/4.0/), which permits unrestricted use, distribution, and reproduction in any medium, provided you give appropriate credit to the original author(s) and the source, provide a link to the Creative Commons license, and indicate if changes were made.

\section{References}

1. X. Ren, H. Fan, C. Wang, J. Ma, S. Lei, Y. Zhao, H. Li, N. Zhao, Magnetic force driven noncontact electromagnetic-triboelectric hybrid nanogenerator for scavenging biomechanical energy. Nano Energy 35, 233-241 (2017). https://doi.org/10.1016/j.nanoe n.2017.03.047 
2. L. Ma, H. Fan, X. Wei, S. Chen, Q. Hu, Y. Liu, C. Zhi, W. Lu, J.A. Zapien, H. Huang, Towards high areal capacitance, rate capability, and tailorable supercapacitors: Co3O4@ polypyrrole coreshell nanorod bundle array electrodes. J. Mater. Chem. A 6(39), 19058-19065 (2018). https://doi.org/10.1039/C8TA07477A

3. M. Stoppa, A. Chiolerio, 4-Testing and evaluation of wearable electronic textiles and assessment thereof, in Performance Testing of Textiles, ed. by L. Wang (Woodhead Publishing, Cambridge, 2016), pp. 65-101

4. M. Abtahi, N.P. Constant, J.V. Gyllinsky, B. Paesang, S.E. D’Andrea, U. Akbar, K. Mankodiya, Chapter 9-WearUp: wearable smart textiles for telemedicine intervention of movement disorders, in Wearable Technology in Medicine and Health Care, ed. by R.K.-Y. Tong (Academic Press, London, 2018), pp. 173-192

5. S.K. Vashist, J.H.T. Luong, Chapter 12-Wearable technologies for personalized mobile healthcare monitoring and management, in Wearable Technology in Medicine and Health Care, ed. by R.K.-Y. Tong (Academic Press, London, 2018), pp. 235-259

6. M.N. Victorino, X. Jiang, C. Menon, Chapter 7-Wearable technologies and force myography for healthcare, in Wearable Technology in Medicine and Health Care, ed. by R.K.-Y. Tong (Academic Press, London, 2018), pp. 135-152

7. L. Dunne, Smart clothing in practice: key design barriers to commercialization. Fash. Pract. 2(1), 41-65 (2010). https://doi. org/10.2752/175693810X12640026716393

8. S.K. Sinha, Y. Noh, N. Reljin, G.M. Treich, S. Hajeb-Mohammadalipour, Y. Guo, K.H. Chon, G.A. Sotzing, Screen-printed PEDOT:PSS electrodes on commercial finished textiles for electrocardiography. ACS Appl. Mater. Interfaces. 9(43), 3752437528 (2017). https://doi.org/10.1021/acsami.7b09954

9. A. Schwarz-Pfeiffer, M. Hoerr, V. Mecnika, Textiles with integrated sleep-monitoring sensors, in Advances in Smart Medical Textiles, ed. by L. van Langenhove (Woodhead Publishing, Oxford, 2016), pp. 197-214

10. B. Taji, S. Shirmohammadi, V. Groza, I. Batkin, Impact of skinelectrode interface on electrocardiogram measurements using conductive textile electrodes. IEEE Trans. Instrum. Meas. 63(6), 1412-1422 (2014). https://doi.org/10.1109/TIM.2013.2289072

11. C. Cochrane, C. Hertleer, A. Schwarz-Pfeiffer, 2-Smart textiles in health: an overview, in Smart Textiles and their Applications, ed. by V. Koncar (Woodhead Publishing, Oxford, 2016), pp. 9-32

12. V. Marozas, A. Petrenas, S. Daukantas, A. Lukosevicius, A comparison of conductive textile-based and silver/silver chloride gel electrodes in exercise electrocardiogram recordings. J. Electrocardiol. 44, 189-194 (2011)

13. A.S. Joutsen, E.S. Kaappa, T.J. Karinsalo, J. Vanhala, Dry electrode sizes in recording ECG and heart rate in wearable applications. EMBEC \& NBC Singapore (2017). https://doi. org/10.1007/978-981-10-5122-7_184

14. J. Crawford, L. Doherty, Practical Aspects of ECG Recording (M\&K Update Ltd, Keswick, 2012)

15. G. Cooper, A.T. Barker, B.W. Heller, T. Good, L.P.J. Kenney, D. Howard, The use of hydrogel as an electrode-skin interface for electrode array FES applications. Med. Eng. Phys. 33(8), 967-972 (2011). https://doi.org/10.1016/j.medengphy.2011.03.008

16. A. Baba, M.J. Burke, Measurement of the electrical properties of ungelled ECG electrodes. Int. J. Biol. Biomed. Eng. 2(3), 89-97 (2008)

17. T. Pola, J. Vanhala, Textile electrodes in ECG measurement, in 3rd International Conference on Intelligent Sensors, Sensor Networks and Information, 3-6 Dec 2007, pp. 635-639

18. T. Linz, L. Gourmelon, G. Langereis, Contactless EMG sensors embroidered onto textile, in 4th International Workshop on Wearable and Implantable Body Sensor Networks (BSN 2007) 2007, pp. 29-34
19. T. Finni, M. Hu, P. Kettunen, T. Vilavuo, S. Cheng, Measurement of EMG activity with textile electrodes embedded into clothing. Physiol. Meas. 28(11), 1405 (2007)

20. D. Pani, A. Dessì, J.F. Saenz-Cogollo, G. Barabino, B. Fraboni, A. Bonfiglio, Fully textile, PEDOT:PSS based electrodes for wearable ECG monitoring systems. IEEE Trans. Biomed. Eng. 63(3), 540-549 (2016). https://doi.org/10.1109/TBME.2015.2465936

21. T.H. Kang, C.R. Merritt, E. Grant, B. Pourdeyhimi, H.T. Nagle, Nonwoven fabric active electrodes for biopotential measurement during normal daily activity. IEEE Trans. Biomed. Eng. 55(1), 188-195 (2008). https://doi.org/10.1109/TBME.2007.910678

22. G. Gold, K. Helmreich, Surface impedance concept for modeling conductor roughness, in IEEE MTT-S International Microwave Symposium, 17-22 May 2015, pp. 1-4

23. L. Casal, G.L. Mura, Skin-electrode impedance measurement during ECG acquisition: method's validation. J. Phys: Conf. Ser. 705, 012006 (2016). https://doi.org/10.1088/1742-6596/705/1/012006

24. S. Kim, R.F. Yazicioglu, T. Torfs, B. Dilpreet, P. Julien, C.V. Hoof, Continuous-time electrode-skin impedance measurement circuit for motion artifact monitoring in ECG acquisition systems, in Symposium on VLSI Circuits, 16-18 June 2010, pp. 219-220

25. C. Assambo, A. Baba, R. Dozio, M.J. Burke, Determination of the parameters of the skin-electrode impedance model for ECG measurement, in Proceedings of the 6th WSEAS International Conference on Electronics, Hardware, Wireless and Optical Communications, Corfu Island, Greece 2007, pp. 90-95. World Scientific and Engineering Academy and Society (WSEAS)

26. M. Stoppa, A. Chiolerio, Wearable electronics and smart textiles: a critical review. Sensors (Basel, Switzerland) 14(7), 1195711992 (2014). https://doi.org/10.3390/s140711957

27. D. Pani, A. Achilli, A. Bonfiglio, Survey on textile electrode technologies for electrocardiographic (ECG) monitoring, from metal wires to polymers. Advanced Material Technology. Special Issue: Electronic Textiles (2018). https://doi.org/10.1002/admt.20180 0008

28. B. Babusiak, S. Borik, L. Balogova, Textile electrodes in capacitive signal sensing applications. Measurement 114, 69-77 (2018). https://doi.org/10.1016/j.measurement.2017.09.024

29. C. Pylatiuk, M. Muller-Riederer, A. Kargov, S. Schulz, O. Schill, M. Reischl, G. Bretthauer, Comparison of surface EMG monitoring electrodes for long-term use in rehabilitation device control, in IEEE International Conference on Rehabilitation Robotics, 23-26 June 2009, pp. 300-304

30. J.-Y. Baek, J.-H. An, J.-M. Choi, K.-S. Park, S.-H. Lee, Flexible polymeric dry electrodes for the long-term monitoring of ECG. Sens. Actuators A 143(2), 423-429 (2008). https://doi. org/10.1016/j.sna.2007.11.019

31. K.-P. Hoffmann, R. uff, Flexible dry surface-electrodes for ECG long-term monitoring, in 29th Annual International Conference of the IEEE Engineering in Medicine and Biology Society, pp. 5739-5742 (2007)

32. E.P. Scilingo, A. Gemignani, R. Paradiso, N. Taccini, B. Ghelarducci, D.D. Rossi, Performance evaluation of sensing fabrics for monitoring physiological and biomechanical variables. IEEE Trans. Inf Technol. Biomed. 9(3), 345-352 (2005). https://doi. org/10.1109/TITB.2005.854506

33. M. Puurtinen, S.M. Komulainen, K. Kauppinen, Malmivuo, J.A.K. Hyttinen, Measurement of noise and impedance of dry and wet textile electrodes, and textile electrodes with hydrogel, in International Conference of the IEEE Engineering in Medicine and Biology Society, pp. 6012-6015 (2006)

34. J. Löfhede, F. Seoane, M. Thordstein, Textile electrodes for EEG recording - a pilot study. Sensors (Switzerland) 12(12), 1690716919 (2012). https://doi.org/10.3390/s121216907 
35. C. Grozea, G. Nolte, F. Popescu, Performance of novel dry electrode EEG cap for evoked potential and band-power activity detection. In Berlin, Heidelberg 2009. World Congress on Medical Physics and Biomedical Engineering, September 7-12, 2009, Munich, pp. 510-513. Springer, Berlin Heidelberg

36. F. Popescu, S. Fazli, Y. Badower, B. Blankertz, K.R. Müller, Single trial classification of motor imagination using 6 dry EEG electrodes. PLoS ONE (2007). https://doi.org/10.1371/journ al.pone. 0000637

37. P.S. Das, M.F. Hossain, J.Y. Park, Chemically reduced graphene oxide-based dry electrodes as touch sensor for electrocardiograph measurement. Microelectron. Eng. 180, 45-51 (2017). https://doi. org/10.1016/j.mee.2017.05.048

38. M. Weder, D. Hegemann, M. Amberg, M. Hess, L.F. Boesel, R. Abächerli, V.R. Meyer, R.M. Rossi, Embroidered electrode with silver/titanium coating for long-term ECG monitoring. Sensors (Switzerland) 15(1), 1750-1759 (2015). https://doi.org/10.3390/ s150101750

39. G. Li, S. Wang, Y.Y. Duan, Towards gel-free electrodes: a systematic study of electrode-skin impedance. Sens. Actuators B 241, 1244-1255 (2017). https://doi.org/10.1016/j.snb.2016.10.005

40. M. Catrysse, R. Puers, C. Hertleer, L. Van Langenhove, H. van Egmond, D. Matthys, Towards the integration of textile sensors in a wireless monitoring suit. Sens. Actuators A 114(2), 302-311 (2004). https://doi.org/10.1016/j.sna.2003.10.071

41. J. Coosemans, B. Hermans, R. Puers, Integrating wireless ECG monitoring in textiles. Sens. Actuators A 130-131, 48-53 (2006). https://doi.org/10.1016/j.sna.2005.10.052

42. G. Mattana, P. Cosseddu, B. Fraboni, G.G. Malliaras, J.P. Hinestroza, A. Bonfiglio, Organic electronics on natural cotton fibres. Org. Electron. 12(12), 2033-2039 (2011). https://doi. org/10.1016/j.orgel.2011.09.001

43. D. Khodagholy, J.N. Gelinas, T. Thesen, W. Doyle, O. Devinsky, G.G. Malliaras, G. Buzsáki, NeuroGrid: recording action potentials from the surface of the brain. Nat. Neurosci. 18, 310 (2014). https://doi.org/10.1038/nn.3905. https://www.nature.com/articles/ nn.3905\#supplementary-information

44. J.V. Lidón-Roger, G. Prats-Boluda, Y. Ye-Lin, J. Garcia-Casado, E. Garcia-Breijo, Textile concentric ring electrodes for ECG recording based on screen-printing technology. Sensors (Switzerland) (2018). https://doi.org/10.3390/s 18010300

45. A. Achilli, A. Bonfiglio, D. Pani, Design and characterization of screen-printed textile electrodes for ECG monitoring. IEEE Sens. J. 18(10), 4097-4107 (2018). https://doi.org/10.1109/ JSEN.2018.2819202

46. U. Lang, N. Naujoks, J. Dual, Mechanical characterization of PEDOT:PSS thin films. Synth. Met. 159(5), 473-479 (2009). https://doi.org/10.1016/j.synthmet.2008.11.005

47. A. Ankhili, X. Tao, C. Cochrane, V. Koncar, D. Coulon, J.M. Tarlet, Comparative study on conductive knitted fabric electrodes for long-term electrocardiography monitoring: silver-plated and PEDOT:PSS coated fabrics. Sensors (Basel) (2018). https://doi. org/10.3390/s18113890
48. G. Medrano, L. Beckmann, N. Zimmermann, T. Grundmann, T. Gries, S. Leonhardt, Bioimpedance spectroscopy with textile electrodes for a continuous monitoring application. In Berlin, Heidelberg 2007. 4th International Workshop on Wearable and Implantable Body Sensor Networks (BSN 2007), pp. 23-28. Springer, Berlin Heidelberg

49. V.F. Ribeiro, D.N. Simões, M. Pittol, D. Tomacheski, R.M.C. Santana, Effect of copper nanoparticles on the properties of SEBS/ PP compounds. Polym. Testing 63, 204-209 (2017). https://doi. org/10.1016/j.polymertesting.2017.07.033

50. M.A. Murphy, Towards a sensor based wearable garment for neurorehabilitation-The Wearitmed Consortium. Paper presented at the 10th World Congress for Neurorehabilitation (2018) Mumbai, Indien February 7-10

51. M. Alt Murphy, F. Bergquist, B. Hagström, N. Hernández, D. Johansson, F. Ohlsson, L. Sandsjö, J. Wipenmyr, K. Malmgren, An upper body garment with integrated sensors for people with neurological disorders - early development and evaluation. BMC Biomed. Eng. 1(1), 3 (2019). https://doi.org/10.1186/s4249 0-019-0002-3

52. A. Ozanne, D. Johansson, U.H. Graneheim, K. Malmgren, F. Bergquist, M.A. Murphy, Wearables in epilepsy and Parkinson's disease-a focus group study. Acta (2017). https://doi. org/10.1111/ane. 12798

53. A. Paiva, H. Carvalho, A. Catarino, O. Postolache, G. Postolache, Development of dry textile electrodes for electromiography a comparison between knitted structures and conductive yarns, in 9th International Conference on Sensing Technology (ICST), 8-10 Dec. 2015, pp. 447-451

54. X. An, G.K. Stylios, A Hybrid textile electrode for electrocardiogram (ECG) measurement and motion tracking. Materials (Basel, Switzerland) 11(10), 1 (2018). https://doi.org/10.3390/ma111 01887

55. K. Galić, M. Kurek, M. Ščetar, Barrier properties of plastic polymers, Reference Module in Food Science (Elsevier, Amsterdam, 2018), pp. 1-21

56. M.S. Hedenqvist, Chapter 26-Barrier packaging materials A2Kutz, Myer, Handbook of Environmental Degradation of Materials (Third Edition) (William Andrew Publishing, Norwich, 2018), pp. 559-581

57. Microlab: PicoPress technical manual for users. http://www.micro labitalia.it/wfolder/filescasehistory/file/8.pdf (2012)

58. H. Liu, D. Chen, Q. Wei, R. Pan, A study of the relationship between clothing pressure and garment bust strain, and Young's modulus of fabric, based on a finite element model. Text. Res. J. 81(13), 1307-1319 (2011). https://doi.org/10.1177/0040517510 399961

Publisher's Note Springer Nature remains neutral with regard to jurisdictional claims in published maps and institutional affiliations. 